\title{
Determining the Indicators of Social Capital Theory to Social Network Sites
}

\author{
Tom Sander \\ Economics and Management Department, \\ University of Latvia \\ Riga, Latvia \\ Stud.tom.sander@fh-kufstein.ac.at
}

\author{
Phoey-Lee, Teh \\ Department of Information Systems \\ Sunway University \\ Selangor, Malaysia. \\ phoeyleet@sunway.edu.my
}

\begin{abstract}
The authors theoretical research provided a framework to define and measure social capital in social network sites. This paper determining with a qualitative method the theoretical dimensions of this framework. The result of this paper is the explanation of social capital theory in social network sites under the consideration of the identified indicators. The sample for this case is students, and the research needs further confirmation by other samples and methods. But this paper gives a first interesting insight in social network sites explained with the social capital theory and provides a first guidance for further research projects.
\end{abstract}

Keywords - social capital; social networks sites; qualitative research; expert interviews

\section{INTRODUCTION}

This paper describes the behavior of students on social network sites. The explanations about the use of social network sites support the description of the existence of social capital in social network sites. These give the opportunity to test the indicators of the model of Sander \& Teh [1]. Further describes in this paper included the behavior and the use of social network sites from university students. This gives an insight about the influence of social network sites on the daily life of students.

Reference [1] identified indicators to measure social capital similarity, impact, trust, involvement / engagement, activity, investment and benefits / advantages. These indicators have been identified in the literature to describe social capital. Social capital is a network theory and describes the mechanism in social networks. The results of the qualitative research has evaluates the indicators and if the indicators can be used to explain the mechanism in social network sites and to define social capital in social network sites [1].

This paper starts with a short definition of social capital, social network sites for this research. The next section is a short description of the used method and demographic data. Following is description of results of the qualitative expert interviews. It ends with analysis of the results and provides an answer if the identified indicators are suitable to explain social network sites with the social capital theory. This research is a first step and needs further efforts to generalize the results.

\section{SOCIAL CAPITAL THEORY}

\section{A. Relationship between Individuals}

The social capital theory explains the relationship between individuals. These relationships create a network. The network provides for the individual opportunities to get access to information and resources. This resources and information are an advantage for the individual. The basis for the exchange of resources is trust, reciprocity and investment. Individuals join networks because they have similar interests, same ethical background, living together in the same area or expect a valuable outcome to be member of the social network [2-4]. The internet changed the social capital theory and the "capital" of social capital get a new meaning for example. The internet provides new opportunities to create, maintain and use social networks [5].

The theory describes the advantages and disadvantages to have a relationship to another individual in a social network. This relationship has been changed with the internet. The existence of social capital in social network sites has to be proved and extended [6].

The advantage of social capital for the individual is the access to needed resources and information, to reduce transaction costs or to get a benefit e.g. the access to another individual can be used to get more power [7].

\section{B. Social Network Sites}

Social network sites are platforms in the internet to create, maintain and use social networks. The social network sites provide the opportunity to exchange resources and information, to present an individual and to create content. Further enables the social network site individuals to create relationships between network members and to search for information and share their posting. A case study was performed on the intention to share and re-share among the young adult at Social Network Sites [8]. One of the results had identified that young adults will discuss their topic after their posting at social network site. The social network site can have a private or business character. The social network site exists in the internet and is a technical platform to exchange resources, to maintain relationships and to create content. Prominent social network sites are Linkedin and Facebook [9$13]$. 


\section{METHOD}

The method to explain the mechanism in social network sites and to generate data to compare the theoretical construct with the reality is an expert interview. The expert interview gives the opportunity to describe the situation and provides a first overview about the mechanism in social networks. The expert interview provides a deeper insight of the construct social network site. With open questions is it possible to get an overview about the research field and to identify all valuable issues. Further has the expert interview the advantage to give some new insight in the research field that can be explored with the expert interview. The flexibility and less restriction give the chance to identify the whole research field without overseeing anything. The interview questions has been provided and used for the interview. Interviews are recorded and transliterated into words and documents for the analysis [14].

This research uses 48 interviews from students to explore the behavior of students at social network sites. The defined experts for this qualitative research are using regularly and permanent social network sites. They have to have registered member of social network sites for several years. Their social status is university student. The questionnaire has had only open questions about social network sites and demographic data. The questions are about the use and behavior at social network sites in general. There has been 17 male and 29 female in the sample. The students are mainly between 20 and 26 years old. The oldest person for this sample has been 35 years old. Table I summarized their age distribution.

The participants of the interview are using the internet mainly less than two hours per day. The heaviest user of social network sites has had between 5 and 6 hours per day. The technical change with mobile solutions give the opportunity to be permanent logged in social network sites as a passive user. This user are part of social network sites and use the social network site if they get a message regarding changes, news or receiving a message at their social network site. Than they react on content of social network sites or they are actively provide content to social network sites. That means the use of social network sites has to be divided in active and passive use. The mentioned time in this paper concentrates on the active using time to communicate or to exchange information at social network sites for example. This technical change are responsible for the use of social network sites and can increase the frequency and time to use social network sites. This new kind of way to access social network sites is an extensive difference to real social networks. That changes the situation for social network sites heavily. Social network sites are anytime from any place available with new technical solutions.

TABle I. Age Distribution OF THE SUbJECTS

\begin{tabular}{|c|c|}
\hline Age Range & Frequency \\
\hline $20-23$ & 22 \\
\hline $24-26$ & 22 \\
\hline 27 & 4 \\
\hline
\end{tabular}

All participants of the interviews have been students at universities at the moment. The participants have been mainly students for business related subjects but in addition some students of medical, technical and natural science faculties take part.

\section{DATA ANALYSIS}

The questions did not ask for a specific social network site but as expected is Facebook, the most popular and used network site. The word "Facebook" has been 106 times appeared in all interviews and business networks as "Xing" and "Linkedin" has been 18 times in total. That means the results are mainly related to "Facebook". The results will present if private social network sites would be considered of the use of students from Germany and Malaysia.

\section{A. Reasons of Using Social Network}

Subjects are allowed to express freely while answering the open questions. The expressions were categorized conceptually into three category, which identified as 1) Communication, 2) Maintain Friendship and 3) Information. Table II shows the frequency of subjects expressed with their reasons.

As summarized in Table II, the main reasons for students to use social network is to maintain friendship. Social network offers to the students to stay in touch with friends on a global basis. That means they can use the social network site worldwide and have the opportunity to collect information about their friends who are not staying next to them or friends who has been met on holidays or international exchange programs. Some of the students mention that they use social network sites to stay in touch with their family who lives far away or to stay in touch with old school friends. The social network site gives the opportunity to take care and to take part in the life of friends who are living in another region. To overcome one's inhibitions to get in touch with another person is more easily. The social network site support and remove barriers to create a relationship with another person. The access to information is more easily and fewer barriers than in the reality. The maintenance of relationship is important today. The social network site members have the opportunity to reanimate "lost" friends or to identify new friends. That increases the social network of the individual via the social network site. Social network sites help to create relationships, which can be useful in future to get access to employment opportunities or to be successful for example. A small group of students mention explicit that social network sites can be used to identify employment or employees.

The second reason to be member in social networks is to get information. Twenty-seven of the students described the

Table II. The Reasons to Use Social Network Sites

\begin{tabular}{|l|c|}
\hline \multicolumn{1}{|c|}{ Reason } & Frequency/48 \\
\hline Maintain Friendship & $38 / 480.79$ \\
\hline Exchange of Information & $27 / 480.56$ \\
\hline Peer Pressure & $18 / 480.38$ \\
\hline Communication & $12 / 480.25$ \\
\hline
\end{tabular}


social network site as a place to exchange information. They are using the social network sites to give access to study materials like tests or to discuss answers in their social network sites group. The students use social network sites to keep posted about news, their friends and families worldwide. They are searching for information about companies, people or other topics of interest in social network sites. They are creating groups at social network sites to fulfill their needs and desires. They use the social network site to coordinate events and to organize their daily life. But they are not only exchanging information about university related topics. Further they exchange information about music events, share links to interesting pages or exchange picture for example. They use their social network site to identify information or to share experience. The information is for a long duration available. The social network site provides a place to discuss, arrange or find solutions for the daily life and university related issues. The advantage of the social network site membership can be exclusive information. Another advantage is the coordination of large groups and to reach many individuals at once with the communication channel social network site.

Another important mentioned point is peer pressure. The students describe that they would miss information if they would not be member in a social network site and they would be not completely integrated. They need social network sites to get access to needed information. Without a membership in a social network site individuals are banned from the community. They do not have access to important information about other people or events for example. This missing link can be crucial for their success at university. Information is important to communicate with each other and to take part in discussions. Any important information is provided on the social network site and keeps the member of the social network site posted. The social network site provide a place to present information and opinions, the students use their pin wall to give their knowledge and experience to other individuals or to exchange empathy to each other. That is a reason to join social networks to spread information to other individuals and to maintain with this activity the relationship.

Last reason is communication. Students are using social network sites to communicate with each other. They use the social network site to chat with other social network site members or to send messages via the social network site platform. The communication is without any cost and faster than e-mails or other channels in the opinion of the students. The sensation of the students is that the communication with social network sites is quicker and easier than to use text messages or phones.

One impact mentioned by students is the selfpresentation. The self-presentation can create envy or used to present an individual to the community to have an advantage. Further is the self-presentation from the perspective of the individual and that can bias the information at social network sites about individuals. That is a negative aspect, but students present them more positively than the reality.

\section{B. Expectation, Join or Leave the Social Network Sites}

This section discusses the expectation, requirement to join, stay or to leave the Social Network Sites. This question completes the focus of student opinion, use and behavior about social network sites.

The answers expand and confirm the described points in Table III. Data protection is a large issue, which in addition describe by the subjects that the missing of real meetings as a negative result of social network sites, that the private relationship suffering. Without real meetings is it not possible to verifying the information about the other social network site member. The opportunity of a fake account at social network sites, misuse of accounts or wrong information is in social network sites possible and can have negative consequences. The change of the communication from real communication to online communication can be at disadvantage. The online communication can have the result of more misunderstandings and conflicts. Misinterpretation of information or content at social network sites is a typical conflict that can be avoided with real meetings. The realities in social networks sites are evaluated critical from students because the opportunity to present only desirable events, positive things or the own opinion is given. For example to fake pictures or to misuse content from other individuals is a critical point. There is clearly described that social network site members provide too many information and that they are not aware about the consequences of their behavior. Students are aware that their data and data at social network sites can be misused. They are frightened that they lose the control about their private data or posted information is out of their sphere and influence. The transparent individual is a result of the social network site and makes the individual glassy. Another point is cyber mobbing. Individuals use the social network sites to disrepute other individuals. Further is it possible that content of individuals get critical or unexpected comments. In addition mention the subjects that criminals or unauthorized individuals can misuse personal data. The dependency can be negative for the individual. The invested time in social network sites can increase on a damaging level for the individual. These individuals are encapsulating from the reality. The increasing numbers of information at social network sites make it more and more difficult to have an overview. The positive point is that the subjects are aware about these points and they protect themselves. This issue influence their behavior and use at social network sites. They reduce the provided content and privacy information at social network sites for example. They are careful with information they receive and know about the

TABLE III. EXPECTATION TO BE OF INTEREST

\begin{tabular}{|c|c|}
\hline Description & Frequency $/ 48$ \\
\hline Data Protection & $28 / 480.58$ \\
\hline Usability & $17 / 480.35$ \\
\hline Information of Interest & $15 / 480.31$ \\
\hline Other & $8 / 48 \quad 0.17$ \\
\hline
\end{tabular}


transparency of them at social network sites. One important point of social capital is trust. It is clearly described above that the trust in social network sites without personal contact is heavily influenced. The members of social network sites are afraid about their data and the trust to other members depends heavily on real relationships.

\section{Determining the Indicators of Social Capital Theory}

The first point which Sander and Teh [1] mentioned in their paper is similarity. The definition referred to the sample of subjects, including those that have the same educational background or educational level. The age is similar and the interest of students is mainly similar. The reason to be a member in the network and to exchange resources is given by similarity as all of the samples have the same situation. The main use of Facebook and membership in related groups to university issues shows that individuals with similar interests and situation join the same network. The value of the social network site is the member. The involvement of other participants in the network is important to create a valuable social network. That means the size of the network is important and the social network site should have all friends as member to make the coordination, exchange and maintenance of relationships more easily and quickly. Further are the opportunity to get access to information or other valuable things is related to the member of the network and the opportunity to collect data about other individuals depend on the network members and opportunities of the social network site [15].

Trust is another important point and the results of the expert interview describes clearly that trust in social network sites is important. The subjects mention that there is a large issue with data protection and the cases that individuals can cheat them related to the case that they do not have a real relationship. The opportunity to penalize a member who is doing wrong is decreased in social network sites. The power and control about data and content is limited in social network sites. The impact on each other is decreased. The misuse of data has to be under consideration to describe the behavior and use of social network sites. The subjects are careful with their presented data and aware that there are risks in social network sites. Another point are comments and critics on content. The social network site provides the opportunity to create content. Subjects are aware that comments can be criticized and information can be misused. That means the offering of information needs trust and subjects regulate the access to their personal information and provide content only to a selected group to protect themselves or their friends who are part of the content. The issues regarding trust has to be under consideration to explain the behavior of individuals at social network sites [16], [17].

The impact of network members on each other can be done by comments, creating content or providing information. The impact on each other is the reaction on activities of other network members. This behavior has been done to impact each other and to lead individuals. The danger is that some people would not like to be criticized and they would not provide information to the audience. This is a large issue because this situation damages the social capital and access to information.

The exchange of information at social networks is clearly described by the outcomes of the interviews. The information can be categorized in private, business or study related information to be updated and informed about important points. Further from Table III is information needed to maintain or to create relationship. The subjects are explaining that they exchange relevant information that supports them with their studies. That means they invest their knowledge and experience to share this information to another individual of their network. That investment needs time and to get results, experience or information needs efforts. The valuable content for the group support other social network sites member to organize and coordinate their daily life. In addition use social network sites to exchange content of interest for their private life, leisure time and hobbies e.g. evaluation of cinema movies, picture or music files. These exchanges have a valuable result for the subjects and increase the capital of the social network site. The exchange of resources in social network site and the social capital theory have one gap. The social network site provides only opportunities to exchange intangible products. The measurement of intangible products can be difficult. The social capital theory has to take under consideration if social capital can exist without the exchange of tangible resources or to concentrate more on the result of the behavior of social network sites member to explain social capital theory as an advantage for social network site members.

Communication is an import point for the social network site and for the exchange process. The students use social network sites to reduce the distance and time to meet each other in reality. Social network sites offer the exchange of information faster and easier. That reduces the investment for group works and is a valuable result for the students because they can safe time or expenses to travel to a place.

The subjects have an impact on each other because they can use their social network to influence each other. The subjects report about cyber mobbing or negative comments on their content in the social network site. This gives the indication that there exists an impact in social network sites. The engagement of individuals in social network sites is described with the exchange of resources and coordination of events. They have to be part of the social network site to be part of the group that is a group pressure and largest impact of social network sites. If they are not part of the social network site than they would miss important information and discriminate. They would not have access to important information if they were not part of the social network site. The main investment of individuals in this sample is university related materials and information for private issues e.g. events. Further invest any network member time to use social networks but the time can be dangerous if it is as mentioned by the students is a consequence of dependency. 


\section{CONCLUSION}

This paper describes the behavior and use of social capital in social network sites. The indicators of Sander and Teh [1] are confirmed and useful to measure social capital in social network sites. The research is under the limitation of subjects population and the generalization is not completely given as it is a qualitative research but this paper shows that social capital exist in social network sites and can be used to explain causal mechanism in social network sites. For example the maintenance of relationship is one dimension of the frame of Sander / Teh to describe social capital. The results of the paper give the indication that maintenance of friendship is an important point for social network sites members.

Further describes the behavior and use of student in social network sites. This gives an insight of the operation of social network sites and that people use their social network site membership to have an advantage and describes the worries of individuals about social network sites and their membership in social network sites.

The students use the social network site for different reasons but they join social network sites for their benefits and advantages. They take part in their student groups, which would be not possible without social network sites because they exchange important relevant information about their studies, and organize their daily life e.g. leisure time. They invest time to maintain their friendship and to be updated. The results of their membership in the social network are beneficial information to be successful at university and to organize their private life.

The exchange in social network sites is limited on intangible an resource which has to be under consideration for the social capital theory and if there are changes in the exchange behavior because the exchanged resources are all at the first moment intangible. Trust is another important point, as people do not have the full control about their content and data. Subjects are aware about that and this issue can be a reason to change behavior and to be more careful in the exchange of resources and providing information.

The technical change with smart phones and other mobile technical products or new platforms and software provides new opportunities and situation which have to be under consideration to expand the social capital theory on social network sites to explain the phenomena at social network sites theoretically.

\section{REFERENCES}

[1] T. Sander and P. L. Teh, "A concept to measure social capital in social network sites," International. Journal of Future Computing. Communication., vol. 3, no. 2, 2014.

[2] M. S. Granovetter, "The strength of weak ties," American Journal of. Sociology., vol. 78, no. 6, pp. 1360 - 1380, 1973.

[3] J. Coleman, "Social capital in the creation of human capital," Am. J. Sociol., vol. 94, no. 1988, pp. 95 - 120, 1988.

[4] J. F. Helliwell and R. D. Putnam, "Economic growth and social capital in Italy," in Social Capital: A Multifaceted Perspective, P. Dasgupta and I. Serageldin, Eds. Washington D.C., 1999, pp. 253 - 268.

[5] N. Lin, "Building a network theory of social capital," in Social Capital Theory and Research, N. Lin, K. Cook, and R. Burt, Eds. New Jersey, 2001, pp. 3 - 30 .

[6] N. B. Ellison, C. Steinfield, and C. Lampe, "The benefits of facebook 'friends:' Social capital and college students'use of online social network sites," Journal of Computer-Mediated Communication, vol. 12 , pp. $1143-1168,2007$.

[7] P. Adler and S.-W. Kwon, "Social capital: Prospects for a new concept," Academic of Management Review., vol. 27, no. 1, pp. 17-40, 2002.

[8] P. L. Teh, L. P. Huah, and Y.-W. Si, "The intention to share and reshared among the young adults towards a posting at social networkin sites," in New Perspectives in Information Systems and Technologies, A. Rocha, A. M. Correia, F. B. Tan, and K. A. Stroetmann, Eds. Heidelberg: Springer Berlin Heidelberg, 2014, pp. 13 - 21

[9] I. Varlamis and I. Apostolakis, "Use of virtual communities for the welfare of groups with particular needs," Journal on Information Technology in Healthcare, vol. 4, no. 6, pp. $384-392,2006$

[10] J. H. Kietzmann, K. Hermkens, I. P. McCarthy, and B. S. Silvestre, "Social media? Get serious! Understanding the functional building blocks of social media," Bus. Horiz., vol. 54, no. 3, pp. 241-251, May 2011.

[11] C. C. Chen, T. H. Y. Chiu, Y.-J. Joung, and S. Chen, "An examination of online social network properties with tie-strength," AIS Electron. Libr., 2011.

[12] M. Häsel, "Opensocial: An enabler for social applications on the web," Commun. ACM, vol. 54, no. 1, p. 139, Jan. 2011.

[13] D. M. Boyd and N. B. Ellison, "Social network sites: Definition, history, and scholarship," J. Comput. Commun., vol. 13, no. 1, pp. 210-230, Oct. 2007.

[14] S. Q. Qu and J. Dumay, "The qualitative research interview," Qual. Res. Account. Manag., vol. 8, no. 3, pp. 238-264, 2011.

[15] S. Franke, "Measurement of social capital," Reference document for public policy research, development, and evaluation, Annals of ., vol 896, no. September. New York, New York, USA: Policy Research Initiative, 2005, pp. 1 - 68 .

[16] C. Li and J. Bernoff, Groundswell, Winning in a World Transformed by Social Technologies. Boston: Harvard Business Review Press, 2011, pp $1-332$.

[17] J. Bernoff and T. Schadler, Empowered. Boston: Harvard Business Review Press, 2010, pp. 1 - 252 